\title{
Anti-Angiogenic Activity of Gecko Aqueous Extracts and its Macromolecular Components in CAM and HUVE-12 Cells
}

\author{
Zhen Tang, Shu-Qiong Huang, Jian-Ting Liu, Gui-Xiang Jiang, Chun-Mei Wang*
}

\begin{abstract}
Gecko is a kind of traditional Chinese medicine with remarkable antineoplastic activity. However, undefined mechanisms and ambiguity regarding active ingredients limit new drug development from gecko. This study was conducted to assess anti-angiogenic properties of the aqueous extracts of fresh gecko (AG) or macromolecular components separated from AG (M-AG). An enzyme-linked immunosorbent assay (ELISA) approach was applied to detect the vascular endothelial growth factor (VEGF) secretion of the tumor cells treated with AG or M-AG. The effect of AG or M-AG on vascular endothelial cell proliferation and migratory ability was analyzed by tetrazolium dye colorimetric method, transwell and wound-healing assays. Chick embryo chorioallantoic membrane (CAM) assays were used to ensure the anti-angiogenic activity of M-AG in vivo. The results showed that AG or M-AG inhibited the VEGF secretion of tumor cells, the relative inhibition rates of AG and M-AG being $27.2 \%$ and $53.2 \%$ respectively at a concentration of $20 \mu \mathrm{L} / \mathrm{mL}$. AG and M-AG inhibited the vascular endothelial (VE) cell proliferation with IC50 values of $11.5 \pm 0.5 \mu \mathrm{L} / \mathrm{mL}$ and $12.9 \pm 0.4 \mu \mathrm{L} / \mathrm{mL}$ respectively. The VE cell migration potential was inhibited significantly $(p<0.01)$ by the AG $(\geq 24 \mu \mathrm{L} / \mathrm{mL})$ or $\mathrm{M}-\mathrm{AG}(\geq 12 \mu \mathrm{L} /$ $\mathrm{mL}$ ) treatment. In vivo, neovascularization of CAM treated with M-AG was inhibited significantly $(p<0.05)$ at a concentration of $0.4 \mu \mathrm{L} / \mathrm{mL}$. This study provided evidence that anti-angiogenesis is one of the anti-tumor mechanisms of $\mathrm{AG}$ and $\mathrm{M-AG}$, with the latter as a promising active component.
\end{abstract}

Keywords: Gecko - anti-angiogenesis - aqueous extracts - macromolecular component - vascular endothelial growth

Asian Pac J Cancer Prev, 16 (5), 2081-2086

\section{Introduction}

Cancer is still a malignant disease which is difficult to cure and with higher mortality rate. Although radiotherapy, surgery and chemotherapy, as regular therapies in clinic, could relieve the symptoms of patients to some extent, the toxic side effects of these treatments shouldn't be ignored (Sinclair, 1998). Traditional Chinese medicine (TCM), a treasure trove evolved over thousands of years, was more widely used to treat malignant tumors in Chinese clinic due to its multi-target therapy and multilevel regulation (Sun, 2014; Liu et al., 2015).

Gecko, also known as shou gong, the most species-rich group of lizards, has been used in TCM for hundreds of years. As "Compendium of Materia Medica" recorded, gecko could cure "Blood plot into a ruffian, Pandora wind scrofula". Modern pharmacology studies have shown that gecko and prescriptions containing it are effective to treat malignant tumors, tuberculosis, osteomyelitis and syrinx. Recently, gecko has been increasingly concerned by the medical world due to its strong anti-tumor activity, especially for digestive system tumors such as esophageal cancer, gastric cancer, and liver cancer (Jiang et al., 2014). Jin Long capsule, fresh gecko as the main ingredients, was a successful case and the sales had been in the top 10 list of antineoplastic Chinese patent medicines for several years in TCM hospital (Yang et al., 2003; Zeng, 2012). Although the antitumor activity of gecko is explicit, the investigation of mechanism and active substance is still superficial (Jiang et al., 2014).

Our laboratory has investigated the antitumor effect and active substance of gecko for many years, especially for liver cancer. We confirmed that AG could inhibit the growth of tumor in $\mathrm{H} 22$ (mouse hepatocellular carcinoma cell line H22) hepatocarcinoma-bearing mice (Hou et al., 2008). In order to illuminate the antitumor components, AG was separated into small molecular components (S-AG), macromolecular components (M-AG) and the valley fractions (V-AG) by Sephadex G-25, M-AG has been proved to have highly antineoplastic activity by previous studies in our group (data not given), it meant that M-AG was a promising active component. In vitro, AG or M-AG was found to have an inhibitory effect on the proliferation of BEL-7402 (Human hepatocarcinoma cell line). In addition, they could decrease the vascular endothelial growth factor (VEGF) secretion of BEL-7402. This suggested that AG and M-AG may have an effect on angiogenesis. Angiogenesis, a required progress for 
tumor growth (Folkman, 1972), is regarded as a promising therapeutic strategy for oncotherapy (Polverini, 2002; Li et al., 2014). Thus, this study is set to investigate the effect of $\mathrm{AG}$ or $\mathrm{M}-\mathrm{AG}$ on angiogenesis.

\section{Materials and Methods}

\section{Materials}

Gecko (Gekko swinhonis Guenther) was collected from Duoshi Town, Jiyang, Jinan City, Shandong Province, China. Gecko was identified by Huzhan Zheng, professor of Beijing University of Chinese Medicine. All the specimens were deposited at the $-80^{\circ} \mathrm{C}$ refrigerator in Department of Biological pharmaceutics, School of Chinese Materia Medica, Beijing University of Chinese Medicine.

Dulbecco's Modified Eagle Medium (DMEM) and RPMI-1640 medium were purchased from Gibco (GrandIsland, NY, USA). Foetal bovine serum (FBS) was purchased from Hangzhou Sijiqing Biological Engineering Materials Co., Ltd. (Hangzhou, China). Trypsin, DMSO (dimethyl sulfoxide), 3-(4, 5-dimethylthiazol-2-yl)-2, 5-diphenyl-tetrazolium bromide (MTT) and microporous membrane $(0.22 \mu \mathrm{m})$ were obtained from Beijing BioDee BioTech Corporation Ltd. (Beijing, China). Transwell (8- $\mu \mathrm{m}$ pore size) was purchased from Corning Costar (Cambridge, MA, USA). The enzyme-linked immunosorbent assay (ELISA) kit for human VEGF was purchased from Sangon Biotech (Shanghai) Co., Ltd. (Shanghai, China). Eggs were obtained from the Institute of Laboratory Animals, China Agricultural University.

\section{The preparation of $A G$ and $M-A G$}

Three hundred grams of gecko died of frost were put into a mortar, containing $1200 \mathrm{~mL}$ of sterile water, with continuous grinding for one hour in ice. Crude tissue homogenates were repeatedly frozen to $-80^{\circ} \mathrm{C}$ and thawed in room temperature for five times. The crude tissue homogenates were filtered by filter paper, using a Buchner funnel and water suction, then were centrifuged for $10 \mathrm{~min}$ at 12,000 rpm. The supernatants were then filtered through a microporous membrane $(0.22 \mu \mathrm{m})$ and collected as the AG. In order to obtain M-AG, AG (no more than $10 \%$ of column volume) was loaded onto a Sephadex G-25 column (Pharmacia, Cambridge, MA, USA) previously equilibrated with high purity water. The column was eluted with high purity water at $1.0 \mathrm{~mL} / \mathrm{min}$. The fractions were monitored at A280, the elution monitored as first peak was collected as M-AG. AG and M-AG was freeze-dried by a vacuum freeze drier (FD-1A-50, Beijing, China) and the freeze-dried powders were dissolved in high pure water respectively as the stock solution $(1 \mathrm{~mL}$ stock solution was obtained from $2.5 \mathrm{~g}$ of fresh gecko), which was used in the subsequent experiment.

\section{The analysis of $A G$ and $M-A G$}

AG was monitored by Sephadex G-25 column at A280 as mentioned above. To maintain the stable quality of the M-AG for each preparation, HPLC was used to check the components of the M-AG. The chromatographic column TSK-Gel G4000PW ${ }_{\mathrm{XL}}(7.8 \times 300 \mathrm{~mm}, \mathrm{HOSOH}$, Japan) was chosen. Pure water was used to be the mobile phase and the flow rate was $0.8 \mathrm{~mL} / \mathrm{min}$. The detection wavelength was $280 \mathrm{~nm}$, and the column temperature was $25^{\circ} \mathrm{C}$.

\section{Cell lines and cell culture}

Human umbilical vein endothelial cells 12 (HUVE12) and human hepatoma cell line BEL-7402 were purchased from Shanghai cell Biology Institute of Chinese Academy of Sciences (Shanghai, China). HUVE-12 cells were cultured in DMEM medium supplemented with $10 \%$ FBS and BEL-7402 cells were cultured in RPMI 1640 medium with $10 \%$ FBS. All cells were grown in a humidified atmosphere, containing $5 \% \mathrm{CO}_{2}$ at $37^{\circ} \mathrm{C}$.

VEGF Enzyme-linked Immunoadsorbent Assay (ELISA)

The ELISA kit specific for human VEGF (Sangon, China) was used to quantify VEGF secretion of BEL-7402. BEL-7402 cell was plated in 6-well plates at a density of $2 \times 10^{5}$ cells /well. Cells were cultivated with serum-free RPMI 1640 medium containing AG or M-AG ranging from $4 \mu \mathrm{L} / \mathrm{mL}$ to $20 \mu \mathrm{L} / \mathrm{mL}$ for $24 \mathrm{~h}$, then the medium was collected and centrifuged at $2000 \mathrm{rpm}$ for $10 \mathrm{~min}$ at $4^{\circ} \mathrm{C}$. The next actions were performed as the ELISA Kit Instruction Manual described.

\section{Cell proliferation assay}

The proliferation of the HUVE-12 cells was detected by the tetrazolium dye colorimetric assay. HUVE-12 cells growing in the log phase were treated with trypsin and suspended as single-cell suspension. Then, the cells dispersed evenly in DMEM medium were seeded in a 96-well plate with a density of 4000 cells/well and treated with various concentrations of AG, M-AG or high purity water as a negative control with six replicates of each treatment. After cultivating for $72 \mathrm{~h}$ in a humidified atmosphere, containing $5 \% \mathrm{CO}_{2}$ at $37^{\circ} \mathrm{C}, 50 \mu \mathrm{g}$ of MTT was added to each well for addition of $4 \mathrm{~h}$ incubation. After discarding the supernatant, the formazane product was dissolved in $150 \mu \mathrm{L}$ of DMSO. Then, the optical density was measured at $570 \mathrm{~nm}$ using a pan-wavelength microplate reader (Model: EPOCH, Serial: \#130315A, BioTek, USA). The relative inhibition of cell proliferation was calculated as follows: relative inhibition $\%=(1-\mathrm{A}$ treated/A control) $\times 100 \%$ (Mosmann, 1983).

\section{In vitro wound-healing assay}

To determine the effects of AG or M-AG on the migration of HUVE-12 cells, an in vitro wound-healing repair assay was performed. HUVE- 12 cells with a density of $4 \times 10^{5}$ cells/well were seeded into 6-well culture dishes and grown in DMEM medium containing $10 \%$ FBS to a nearly confluent cell monolayer. At the confluence, the cell monolayers were wounded using a $20 \mu \mathrm{L}$ micropipette tip. The floating cells were washed away by phosphate buffer saline. Then the cell monolayers with wound were incubated in $1 \%$ FBS DMEM medium containing various concentrations of AG, M-AG or high purity water as a negative control for $24 \mathrm{~h}$. The situation of wound healing was photographed at a $200 \times$ magnification using a microscope (Nikon, Japan). 


\section{Transwell migration assay}

Briefly, $650 \mu \mathrm{L}$ of DMEM medium with $20 \%$ FBS were placed in the bottom chamber of the transwell. Top chambers were seeded with $4 \times 10^{4}$ HUVE- 12 cells in $100 \mathrm{~mL}$ of serum-free medium, where the transwell membrane was coated with $1 \%$ gelatin in order to provide a better adherence. The cells were incubated with various concentrations of $\mathrm{AG}, \mathrm{M}-\mathrm{AG}$ or high purity water (negative control). The migration assay proceeded in a cell culture incubator $\left(37^{\circ} \mathrm{C}, 5 \% \mathrm{CO}_{2}\right)$ for $6 \mathrm{~h}$. Then, the nonmigrated cells on the top surface of the membrane were removed with a cotton swab. The migrated cells on the bottom side of the membrane were fixed in $90 \%$ methanol for $10 \mathrm{~min}$ and washed for three times with sterile water. Further, the HUVE- 12 cells were stained with $1 \%$ crystal violet. The cells that were trapped in or attached to the reverse side of the membrane were photographed by a microscope (Nikon, Japan) at a 100×magnification, and was quantified by manual counting in four microscopic fields per sample at a $400 \times$ magnification. The number of pierced cells represented average of the pierced cells in the four microscopic fields per sample.

\section{Chick embryo chorioallantoic membrane assay}

Anti-angiogenic activity of M-AG was measured by CAM assay as described with minor modification (Brooks et al., 1999). One hundred fertilized eggs which were incubated at $37.5 \pm 0.5^{\circ} \mathrm{C}$ with $65-70 \%$ relatively humidity were divided into five groups, treated with $0,0.4,0.8$, 1.6 or $4 \mu \mathrm{L} / \mathrm{mL}$ M-AG in sequence. On day 7 , a $2.5 \mathrm{~cm}^{2}$ window was cut on the broad side of the egg, which could candle the egg to assure existence of embryonic blood vessels, the shell covering the air sac was punched out and removed by forceps, and the shell membrane on the floor of the air sac was peeled away. Ten microliters of M-AG or high purity water as a negative control was applied on gelatin sponges with $2 \mathrm{~mm}$ in diameter and then placed onto the 7-day-old CAM surface, after which a permeable sticky tape was immediately appended to the window. Three days later, methanol was used to immobilize blood vessels and the vessels were photographed. Antiangiogenic effect of M-AG on CAM was quantified by counting the number of visible microvessels (diameter $<0.05 \mathrm{~mm}$ ) within the defined area of the gelatin sponges.

\section{Statistical analysis}

Student's t-test and one-way analysis of variance (ANOVA) were used to determine the statistical significance of differences between the values for the various experimental and control groups. All data are expressed as the mean \pm S.D. a P-value $<0.05$ was considered statistically significant.

\section{Results}

\section{The analysis of $A G$ and $M-A G$}

Three fraction pools (1 (peak 1, macromolecular components; M-AG), 2 (peak 2, small molecular components; S-AG) and 3 (valley, valley fractions; $\mathrm{V}-\mathrm{AG})$ ) were collected by passing AG through a Sephadex G-25 gel filtration column which was monitored at A280
(Figure 1A). The yields of M-AG, S-AG and V-AG were $5.86 \%, 2.14 \%$ and $1.50 \%$, respectively. Duo to the separation range of Sephadex G-25 is $1-5 \mathrm{kD}$, we inferred that the molecular weight of $\mathrm{M}-\mathrm{AG}$ was more than $5 \mathrm{kD}$, and the molecular weight of S-AG was less than $5 \mathrm{kD}$. M-AG appeared tawny and clear. HPLC method was used to test the components of M-AG. Three main peaks (1, 2 and 3) and several small peaks were observed on the HPLC graph (Figure 1B), and the three main peaks were used to evaluate the sample quality.

\section{Down-regulated secretion of VEGF}

The concentration of VEGF, secreted over the $24 \mathrm{~h}$ period by BEL-7402 cells treated with 4 to $20 \mu \mathrm{L} / \mathrm{mLAG}$ or M-AG, were illustrated as shown in Figure 2. AG or M-AG reduced VEGF secretion in BEL-7402 cells in a dose-dependent manner. M-AG had a stronger effect on inhibiting the secretion of VEGF than AG. At the same concentration of $20 \mu \mathrm{L} / \mathrm{mL}$, the relative inhibition rate of AG for $24 \mathrm{~h}$ was $27.2 \%$, obviously less than that of M-AG (53.2\%). This suggested that M-AG had more intensive suppression on the secretion of VEGF in BEL-7402 cells.

\section{Anti-proliferative effects on HUVE-12 cells}

HUVE-12 (Wang et al., 2010; Lou et al., 2012) which was widely applied in the study of angiogenesis, was chosen to investigate the potential effects of AG or M-AG on vascular endothelial cell viability. HUVE-12 cells were exposed to 6-20 $\mu \mathrm{L} / \mathrm{mL}$ of AG or M-AG for 24-72 h. The dose-dependent inhibitory effects of AG or M-AG were observed at $72 \mathrm{~h}$ (Figure 3). The IC50 of AG or M-AG

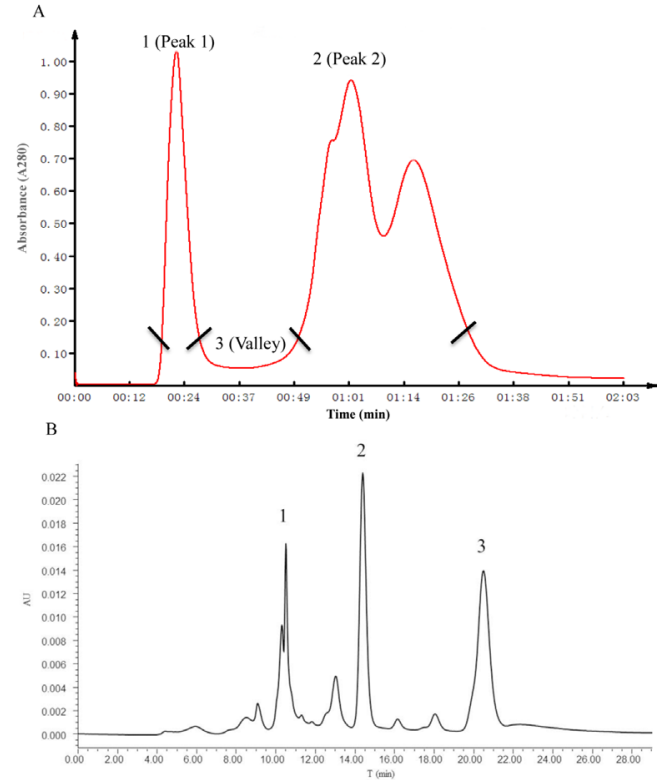

Figure 1. The chemical profiles of AG and M-AG. (A) The chemical profiles of AG. AG was analysed through a Sephadex G-25 gel filtration column. The column was eluted with high purity water at $1.0 \mathrm{~mL} / \mathrm{min}$ and the fractions were monitored at A280. Three fraction pools (1 (peak 1, M-AG), 2 (peak 2, S-AG) and 3 (valley, V-AG)) were obtained. (B) Chromatogram of the HPLC (TSK-Gel G4000PW ${ }_{\mathrm{XL}}$ ) analysis of M-AG. M-AG was analyzed by HPLC. Pure water was chosen to be the mobile phase. The flow rate was $0.8 \mathrm{~mL} / \mathrm{min}$ and the detection wavelength was $280 \mathrm{~nm}$. AU: absorbance unit; 1 : Peak 1; 2: Peak 2; 3, Peak 3 
was $11.5 \pm 0.5 \mu \mathrm{L} / \mathrm{mL}$ and $12.9 \pm 0.4 \mu \mathrm{L} / \mathrm{mL}$ respectively, the maximum inhibitory rate of AG or M-AG was $80.12 \%$ and $65.81 \%$ respectively (Figure $3 \mathrm{~B}$ ).

\section{Inhibitive effects on the migration of HUVE-12 cells}

The wound-healing assay is a classical and commonly subjecting method for studying cell migration (Yarrow et al., 2004). The results of microscopic observation showed that AG or M-AG decreased the migration of HUVE-12 cells in a concentration-time-dependent manner. Almost no cell migration was observed when the cells treated with $40 \mu \mathrm{L} / \mathrm{mL}$ of $\mathrm{AG}$ or $28 \mu \mathrm{L} / \mathrm{mL}$ of M-AG (Figure $4 \mathrm{~A}$ ). In

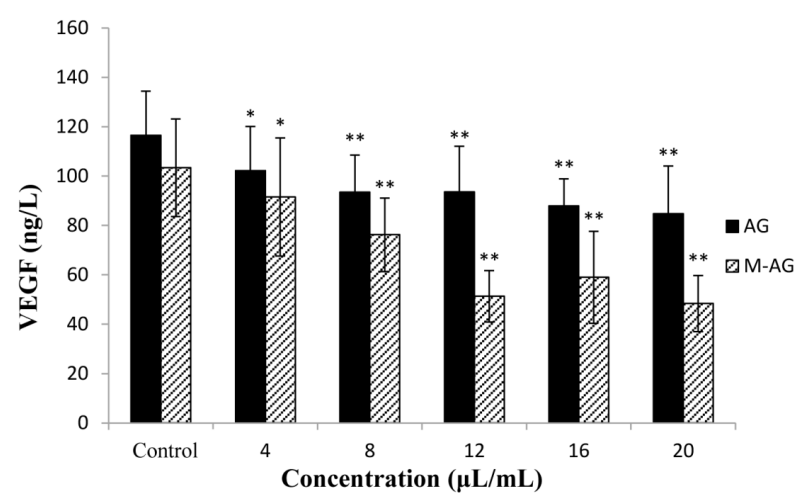

Figure 2. Effects of AG or M-AG on VEGF Secretion of BEL-7402 Cells. The BEL-7402 cells were treated with different concentrations of AG or M-AG for $24 \mathrm{~h}$, then the supernatant was measured as the ELISA Kit Instruction Manual described. Data were presented as mean \pm S.D. The single asterisk (*) indicates a significant difference from the control $(p<0.05)$; the double asterisk $(* *)$ indicates a very significant difference from the control $(p<0.01)$
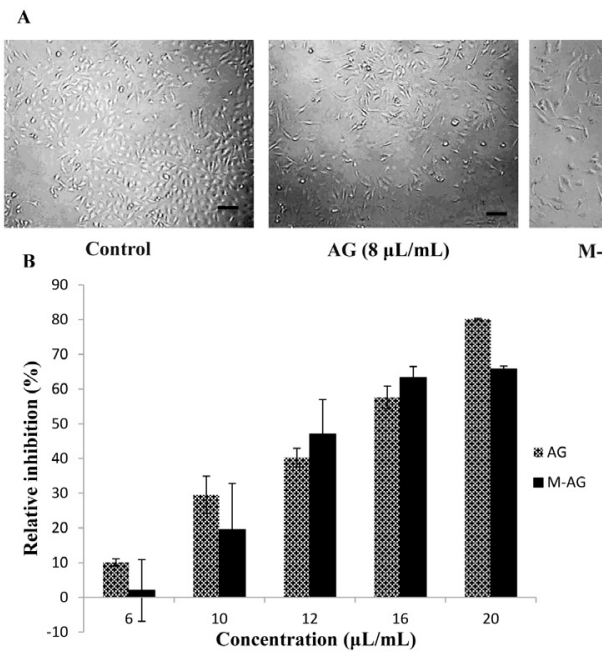

Figure 3. Effects of AG or M-AG on the Morphology and Proliferation of HUVE-12 Cells. HUVE-12 cells were seeded in 96-well plates with a density of 4000 cells/well and treated with $0,6,10,12,16,20 \mu \mathrm{L} / \mathrm{mL}$ of AG or M-AG for 72 $\mathrm{h}$ with six replicates of each treatment, negative control group was treated with high purity water. (A) Morphology of HUVE12 cells treated with various concentrations of AG or M-AG. The figures were photographed at a $200 \times$ magnification. Scale bar $=100 \mu \mathrm{m}$. (B) Relative inhibitory rates of AG or M-AG on HUVE-12 cells proliferation. The light density was measured by using a Pan-wavelength microplate reader at $570 \mathrm{~nm}(\mathrm{n}=4)$ order to quantify the migration degree of HUVE-12 cells, transwell assay was used to determine the inhibitory effect of AG or M-AG migratory activity (Wang et al., 2014). According to the result, the migration potential was inhibited significantly $(p<0.01)$ when HUVE-12 cells treated with AG $(24 \mu \mathrm{L} / \mathrm{mL})$ or M-AG $(12 \mu \mathrm{L} / \mathrm{mL})$ for 6 hours (Figure 4B, C).

\section{Inhibitive effect of $M-A G$ on vessels formation of CAM}

To ensure the inhibitory effect of $\mathrm{M}-\mathrm{AG}$ on angiogenesis in vivo, CAM assay was performed. CAM is a successful model for studying angiogenesis which has been applied in research on morpho-functional aspects of the angiogenesis due to its abundant vascularization and easy accessibility (Auerbach et al., 2003; Chen et al., 2013). The blood vessel was observed under the microscope, the CAMs on the edge of gelatin sponges with high purity water did not show obvious changes in vascular density, and a normal branching pattern of blood vessels was presented. Vascularisation in chick embryo was significantly inhibited by $\mathrm{M}-\mathrm{AG}$ at $0.4 \mu \mathrm{L} / \mathrm{mL}$. The displayed images in Figure 5A show that the vasoganglion at the edge of the gelatin sponge got fuzzy and damaged, as the extension of time and concentration, the damaged area increased gradually and the vascular branch got fractured

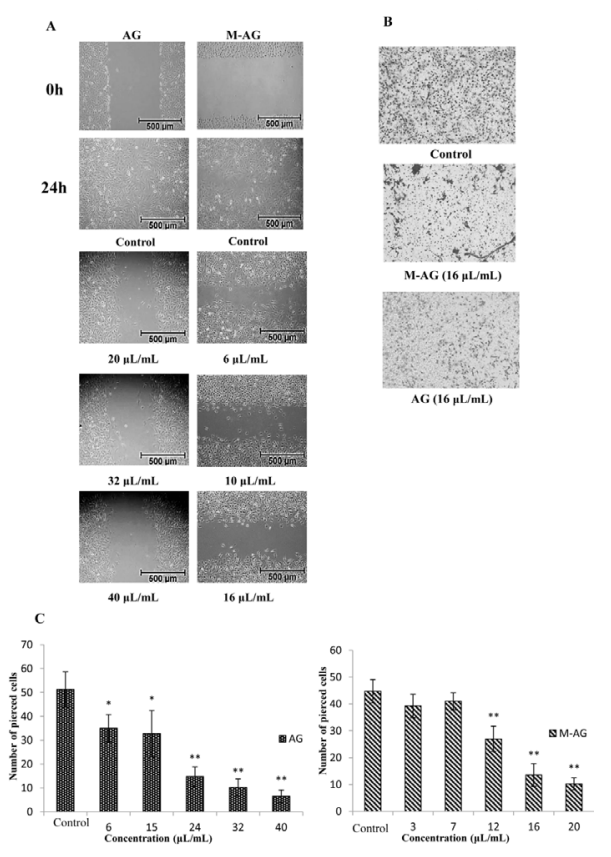

Figure 4. Effects of AG or M-AG on Migration of HUVE-12 Cells. (A) Pictures of cell migration in woundhealing repair assay. HUVE-12 cells were scratched and treated with various concentrations of AG or M-AG for $24 \mathrm{~h}$. Migration was observed under a phase-contrast microscope at a 200 $\times$ magnification. (B) Photos of HUVE-12 cells on the bottom surface of the membrane in transwell assay. Cells were photographed by a microscope at a $100 \times$ magnification (C) Average of the pierced HUVE-12 cells in the four microscopic fields. Data were determined by counting cells in four microscopic fields per sample at a $400 \times$ magnification. Results were presented as mean \pm S.D. $(n=3)$. The single asterisk $(*)$ indicates a significant difference from the control $(p<0.05)$; the double asterisk $(* *)$ indicates a very significant difference from the control $(p<0.01)$ 
A

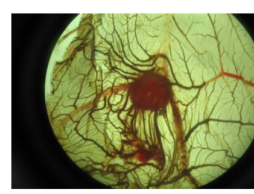

Control

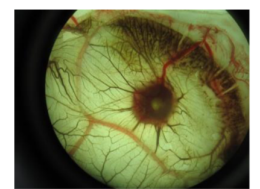

M-AG $(1.6 \mu \mathrm{L} / \mathrm{mL})$

B

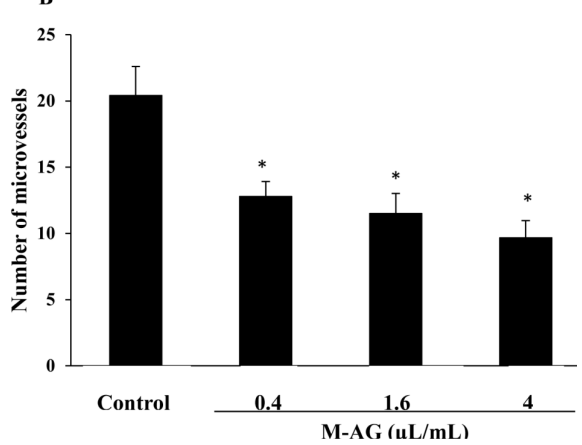

Figure 5. Effects of M-AG on New Vessels Formation in CAMs. Chicken embryos were incubated at $37^{\circ} \mathrm{C}$ with $65 \%$ relative humidity for seven days, then the gelatin sponges adsorbed with various concentrations of $\mathrm{M}-\mathrm{AG}$ or high purity water were placed onto the CAMs surface and incubated for 72 h. Vasculogenesis was quantified by counting the number of visible new vessels (diameter $<0.05 \mathrm{~mm}$ ) within the defined area of the gelatin sponges. (A) Photos of the CAMs with different treatment. (B) The number of newly formed vessels on the edge of gelatin sponges. Results were presented as mean \pm S.D. $(n=$ 3 ). The single asterisk $(*)$ indicates a significant difference from the control $(p<0.05)$; the double asterisk $(* *)$ indicates a very significant difference from the control $(p<0.01)$

and haemolytic. The quantitative results shown in Figure $5 \mathrm{~B}$ indicated that M-AG had an inhibitory effect on angiogenesis of CAMs in a dose-dependent manner. The inhibition ratio of $\mathrm{M}-\mathrm{AG}$ on the formation of new blood vessels was $37.4 \pm 5.6 \%$ at a concentration of $0.4 \mu \mathrm{L} / \mathrm{mL}$.

\section{Discussion}

Ever since the mechanism of tumor angiogenesis was revealed by Folkman's research (Folkman, 1972; Folkman et al., 1987), it is generally accepted today that tumor growth is angiogenesis-dependent, and the anti-angiogenic therapy is also regarded as a promising therapeutic strategy for oncotherapy (Polverini, 2002; Naqane, 2014). Tumors secret various growth factors (e.g. VEGF) which activate receptors on endothelial cells present in pre-existing blood vessels. The activated endothelial cells release proteases to allow endothelial cells to escape from the original (parent) vessel walls. The endothelial cells then proliferate into the surrounding matrix and form solid sprouts connecting neighboring vessels. As sprouts extend toward the source of the angiogenic stimulus, endothelial cells migrate in tandem. These sprouts then form loops to become a full-fledged vessel lumen as cells migrate to the site of angiogenesis. In this study, we showed that both AG and M-AG could reduce VEGF secretion of BEL7402 cells. At a concentration of $20 \mu \mathrm{L} / \mathrm{mL}$, the relative inhibition rate of $\mathrm{AG}$ and $\mathrm{M}-\mathrm{AG}$ effecting on the VEGF secretion was $27.2 \%$ and $53.2 \%$ respectively, suggesting that M-AG had a more intensive inhibition on the secretion of VEGF than AG. AG or M-AG inhibited the HUVE-12 cells proliferation in a dose-dependent way, the IC50 of AG or M-AG was $11.5 \pm 0.5 \mu \mathrm{L} / \mathrm{mL}$ and $12.9 \pm 0.4 \mu \mathrm{L} /$ $\mathrm{mL}$ respectively. The transwell and wound-healing assay demonstrated that both AG and M-AG significantly $(p<0.01)$ inhibited the HUVE-12 cells migration when treated with AG $(24 \mu \mathrm{L} / \mathrm{mL})$ and $\mathrm{M}-\mathrm{AG}(12 \mu \mathrm{L} / \mathrm{mL})$ for 6 hours. All the data proved that VEGF secretion, endothelial cells proliferation and migration, which were key steps for tumor angiogenesis, were blocked partly by AG or M-AG. What's more, M-AG, a macromolecular component with a more than $5 \mathrm{kD}$ molecular weight separated from AG, was proved to have a strong antitumor activity ( $63 \%$ inhibition rate) by previous studies (data not given) through $\mathrm{H} 22$ hepatocarcinoma-bearing mice in vivo. In this research $\mathrm{M}-\mathrm{AG}$ displayed stronger inhibitory effects on angiogenesis, and this activity was further identified by CAM assays. Therefore, we inferred that the major active components from gecko might be macromolecules and anti-angiogenic might be one of the anti-tumor mechanisms of gecko.

Because of the good therapeutic effects in cancer clinical, the active ingredients of gecko were searched by several labs. Gekko sulfated polysaccharide was separated from water extraction of gecko with alcohol precipitation, which showed a differentiation-inducing activity in hepatic cancer cell line SMMC-7721, however, it didn't show anti-tumor activity in mice (Xin et al., 2011). The in vivo anti-tumor effect of the imidazole alkaloids extracted from gecko was reported when it was encapsulated in liposomes (Kang et al., 2009). But there was no report to show if the imidazole alkaloids itself was orally effective while the gecko powder did. The anti-tumor crude peptide separated from gecko was reported but its components still need to be verified (Wu et al., 2013). Therefore, the anti-tumor single active ingredient from the gecko was still need to find. M-AG is a promising resource to find anti-angiogenic component from gecko. With the deepening of research on tumor dormancy, there has been growing attention on the tumor microenvironment, anti-angiogenesis drugs is an instance. However, the development of anti-angiogenic drugs moves slowly, only few were commonly used in clinic. The most common of them was Bevacizumab, a recombinant humanized monoclonal antibody that produces angiogenesis inhibition by inhibiting vascular endothelial growth factor A(VEGF-A) (Los et al., 2007). It is worth noting that Bevacizumab has been proved to have issues of toxicity and drug resistance by the FDA, such as hypertensive crisis, nephritic syndrome and congestive heart-failure. The promising evolutionary trend was to develop multi-target and broad-spectrum angiogenesis inhibitors (Limaverde-Sousa et al., 2014). Separating active substance from TCM is a high-efficiency and secures way for research and development of new drugs due to the multi-targeted and the thousands of years of 
application of TCM. Therefore, M-AG was a promising anti- angiogenic resource for new drug development.

The mechanism of the antitumor activity of gecko was deemed to be various although the studies were not deep enough (Jiang et al., 2014). Several studies indicated that the extracts of gecko could induce the tumor cell apoptosis in vitro (Yang et al., 2007; Song et al., 2011; Jeong et al., 2012). Other data proved that gecko could inhibit the tumor growth by adjusting the immune system (Wu et al., 2008; Liu et al., 2008). Besides, differentiation-inducing activity of gecko was also confirmed by our laboratory (Wang et al., 2014). All of the data indicated that various active substances in gecko had therapeutic action on oncotherapy in different ways. So, making certain what the active substances are and what the mechanism they depend on is still a daunting task.

Our research confirmed that anti-angiogenesis is one of the anti-tumor mechanisms of gecko, M-AG is a promising anti-tumor substance depending on inhibiting anti-angiogenesis and is well worth being researched and separated deeply.

\section{Acknowledgements}

This research was funded by Beijing University of Chinese Medicine Optional Topics Project.

\section{References}

Auerbach R, Lewis R, Shinners B, et al (2003). Angiogenesis assays: a critical overview. Clin Chem, 49, 32-40.

Brooks PC, Montgomery AM, Cheresh DA (1999). Use of the 10-day-old chick embryomodel for studying angiogenesis. Methods Mol Biol, 129, 257-69.

Chen SL, Burnett J, Sun D, et al (2013). Photoacoustic microscopy: a potential new tool for evaluation of angiogenesis inhibitor. Biomed Opt Express, 4, 2657-66.

Folkman J (1972). Anti-angiogenesis: new concept for therapy of solid tumours. Ann Surg, 175, 409-16.

Folkman J, Klagsbrun M (1987). Angiogenetic factors. Scinece, 235, 442-7.

Hou XN, Geng D, Cai A, et al (2008). Comparative research on anticancer activity between fresh and processed gekko subpalmatus. Zhong Yao Cai, 31, 957-9.

Jeong AJ, Chung CN, Kim HJ, et al (2012). Gecko proteins exert anti-tumour effect against cervical cancer cells via PI3-Kinase/Akt pathway. Korean J Physiol Pharmacol, 16, 361-5.

Jiang G, Wang C, Geng D, et al (2014). Advances on the antitumor material finding from gecko and the mechanism research. Curr Opin Complement Alternat Med, 1, 45-8.

Kang JG, Zhang SZ, Li ZZ, et al (2009). Preparation of fresh Gekko swinhon is gunther anti-neoplasm active component alkaloid liposomes and its quality evaluation. Chinese J New Drugs, 18, 1453-8.

Li YP, Tian FG, Shi PC, et al (2014). 4-Hydroxynonenal promotes growth and angiogenesis of breast cancer cells through HIF-1 $\alpha$ stabilization. Asian Pac J Cancer Prev, 15, 10151-6.

Limaverde-Sousa G, Sternberg C, Ferreira CG (2014). Antiangiogenesis beyond VEGF inhibition: a journey from antiangiogenic single-target to broad-spectrum agents. Cancer Treat Rev, 40, 548-57.

Liu F, Wang JG, Wang SY, et al (2008). Antitumour effect and mechanism of Gecko on human esophageal carcinoma cell lines in vitro and xenografted sarcoma 180 in Kunming mice. World J Gastroenterol, 14, 3990-6.

Liu S, Sun Y, Louie W (2015). Symptom distress and its association with traditional chinese medicine use in chineseamerican women with cancer. Oncol Nurs Forum, 42, 24-32.

Los M, Roodhart JML, Voest EE (2007). Target practice: lessons from phase III trials with bevacizumab and vatalanib in the treatment of advanced colorectal cancer. Oncologist, 12, 443-50.

Lou YL, Guo F, Liu F (2012). MiR-210 activates notch signaling pathway in angiogenesis induced by cerebral ischemia. Mol Cell Biochem, 370, 45-51.

Mosmann T (1983). Rapid colorimetric assay for cellular growth and survival: application to proliferation and cytotoxicity assays. J Immunol Methods, 65, 55-63.

Naqane M (2014). Anti-angiogenic therapy for malignant glioma. Gan To Kagaku Ryoho, 41, 141-7.

Polverini PJ (2002). Angiogenesis in health and disease: Insights into basic mechanisms and therapeutic opportunities. J Dent Educ, 66, 962-75.

Sinclair S (1998). Chinese herbs: a clinical review of astragalus, ligusticum, and schizandrae. Altern Med Rev, 3, 338-44.

Song JY, Wang XL, Wang JG, et al (2011). Inhibitory effects of gecko alcohol extract on human esophageal squamous carcinoma cell line EC-109 proliferation and associated mechanism. Zhong Yao Cai, 34, 1020-3.

Sun Y (2014). The role of Chinese medicine in clinical oncology. Chin J Integr Med, 20, 3-10.

Wang C, Cao J, Qu J (2010). Recombinant vascular basement membrane derived multifunctional peptide blocks endothelial cell angiogenesis and neovascularization. J Cell Biochem, 111, 453-60.

Wang F, Hu J, Xiong L, et al (2014). Effects of klotho protein on proliferation, migration, adhesion and vascular endothelial growth factor expression of human umbilical vein cells. Zhonghua Yi Xue Za Zhi, 94, 2207-11.

Wang YX, Gu XX, Geng D, et al (2014). Differentiation of bel-7402 human hepatocarcinoma cells induced by aqueous extracts of fresh gecko (AG) and its anti-tumor activity in vivo. J Ethnopharmacol, 155, 1583-8.

Wu XL, Wang JG, Li RF, et al (2013). Inhibitory effect of Gecko peptides mixture on growth of human esophageal squamous carcinoma cell line EC109 cells. Chin J Clin Pharmacol, 29, 602-4.

Wu XZ, Xie GR (2008). Induced differentiation of hepatocellular carcinoma by natural products. Afr J Tradit Complement Altern Med, 5, 325-31.

Xin L, Wu XZ, Xie GR (2011). Efffects of gekko sulfated polysaccharide on the proliferation and differentiation in hepatic cancer cell line SMMC-7721. Tianjin Med J, 39, 1123-6.

Yang JX, Wang XM, Zhu W, et al (2007). Anti-tumour effects of dry and fresh gekko swinhonis gunther freeze-dried powders on mouse $\mathrm{H} 22$ hepatocellular carcinoma in vivo and in vitro. World Chinese J Digestol, 15, 157-60.

Yang R, Guo JH, Jiang Y (2003). Analysis of application and utilization of anti-tumour drugs and its assistant patent Chinese Drugs. Zhongguo Zhong Xi Yi Jie He Za Zhi, 23, 946-9.

Yarrow JC, Perlman ZE, Westwood NJ (2004). A highthroughput cell migration assay using scratch wound healing, a comparison of image-based readout methods. BMC Biotechnol, 4, 21.

Zeng RX (2012). Analysis of the utilization of antitumour drugs of Chinese patent medicines in our hospital during 2009- 